\title{
Application of the Montreal classification for Crohn's disease to a single clinician database of 1015 patients
}

\author{
Hugh J Freeman MD
}

HJ Freeman. Application of the Montreal classification for Crohn's disease to a single clinician database of 1015 patients. Can J Gastroenterol 2007;21(6):363-366.

Crohn's disease involves different gastrointestinal sites and may be characterized by high rates of strictures and penetrating complications. The present study applied the newly described Montreal schema of classification to a large, prospectively accumulated clinical database. In addition, age dependence was evaluated at diagnosis, with regard to disease location and disease behaviour. There were 1015 consecutively evaluated patients (449 male and 566 female). Disease was most often localized in the ileocolon and was usually complex with stricture formation or penetrating complications. For both sexes, with increasing age at diagnosis, Crohn's disease was less extensive, more often localized in the colon alone and characterized by less complex disease behaviour, especially with less penetrating disease complications. Using the Montreal classification for Crohn's disease, these results define the clinical features in a large, single clinician database and demonstrate age dependence in the phenotypic clinical expression of Crohn's disease.

Key Words: Crohn's disease; Disease behaviour; Disease site; Effects of aging; Montreal classification; Phenotypic expression; Vienna classification

\section{L'application de la classification de Montréal pour la maladie de Crohn à la base de données de 1015 patients d'un clinicien}

La maladie de Crohn touche divers foyers gastro-intestinaux et peut être caractérisée par un taux élevé de rétrécissements et de complications pénétrantes. Pour la présente étude, on a appliqué le nouveau schème de classification de Montréal à une importante base de données cliniques colligée de manière rétrospective. De plus, on a évalué le rapport avec l'âge au moment du diagnostic, compte tenu du foyer et du comportement de la maladie. La base de données contenait 1015 patients évalués consécutivement, soit 449 hommes et 566 femmes. En général, la maladie se situait dans l'iléocôlon et était complexe, car elle s'accompagnait de rétrécissements et de complications pénétrantes. Pour les deux sexes, plus les patients étaient âgés au diagnostic, moins la maladie de Crohn était répandue, se limitant surtout au côlon seul et se caractérisant par un comportement moins complexe de la maladie, notamment des complications moins pénétrantes. Au moyen de la classification de Montréal pour la maladie de Crohn, ces résultats définissent les caractéristiques cliniques de la grande base de données provenant d'un seul clinicien et démontrent le lien avec l'âge de l'expression clinique et phénotypique de la maladie de Crohn.
C rohn's disease is a heterogeneous inflammatory disorder that may affect different sites in the gastrointestinal tract (1). In earlier studies (2-7), using a database accumulated over 20 years, Crohn's disease was defined as a predominantly female disorder, often familial, and usually characterized by a high rate of stricture formation and penetrating disease complications.

Recently, efforts have focused on defining more homogeneous patient groups with specific molecular, genetic or serological markers (eg, antineutrophil cytoplasmic autoantibodies and anti-Saccharomyces cerevisiae antibodies), or clinical characteristics, such as patient age at diagnosis, disease location and disease behaviour (8). At the recent World Congress of Gastroenterology in Montreal, Quebec (9), a classification for Crohn's disease was presented by an expert group to replace the prior Vienna schema (8). The main changes included refinement of age groups at diagnosis (ie, to include a pediatric group 16 years of age or younger); introduction of an upper gastrointestinal disease site modifier (ie, so as to not disregard disease localization in the ileum, colon and ileocolon, if concomitant upper gastrointestinal tract involvement was present); and the introduction of a perianal disease modifier (ie, to permit independent definition of disease behaviour categories, including strictures or other penetrating disease complications).

The present study applied this new Montreal schema to a large consecutively evaluated Crohn's disease database propectively accumulated over 20 years of clinical practice and further explored the age-dependent phenotypic clinical expression at different sites along the gastrointestinal tract, as well as disease behaviour.

\section{PATIENTS AND METHODS}

\section{Definitions and inclusions}

Patients were derived from a clinical database containing information on over 1015 consecutively evaluated patients with Crohn's disease, defined using a combination of clinical, endoscopic, imaging and pathological investigations, and directly treated by the investigator over more than two decades (July 1979 to June 2003). The mean period of direct patient follow-up was over 10 years with a range from three to 26 years, but records were available for some for over 50 years (2-7). In an earlier preliminary report using the

Department of Medicine (Gastroenterology), University of British Columbia, Vancouver, British Columbia

Correspondence: Dr Hugh Freeman, Gastroenterology, UBC Hospital, 2211 Wesbrook Mall, Vancouver, British Columbia V6T 1W5.

Telephone 604-822-7216, fax 604-822-7236, e-mail hugfree@shaw.ca

Received for publication March 28, 2006. Accepted July 19, 2006 
TABLE 1

Single clinician database of 1015 Crohn's disease patients (n=1015)

\begin{tabular}{lcccc}
\hline & $\begin{array}{c}\text { All, } \\
\mathbf{n}(\%)\end{array}$ & $\begin{array}{c}<\mathbf{1 7} \text { years, } \\
\mathbf{n}(\%)\end{array}$ & $\begin{array}{c}\mathbf{1 7 - 4 0} \text { years, } \\
\mathbf{n}(\%)\end{array}$ & $\begin{array}{c}>\mathbf{4 0} \text { years, } \\
\mathbf{n}(\%)\end{array}$ \\
\hline $\begin{array}{l}\text { Sex } \\
\text { Male }\end{array}$ & $449(44.2)$ & $52(45.6)$ & $318(43.4)$ & $79(46.7)$ \\
$\quad \begin{array}{l}\text { Female } \\
\text { Site }\end{array}$ & $566(55.8)$ & $62(54.4)$ & $414(56.6)$ & $90(53.3)$ \\
L1 & $268(26.4)$ & $25(21.9)$ & $201(27.4)$ & $42(24.9)$ \\
L2 & $313(30.8)$ & $24(21.1)$ & $206(28.1)$ & $83(49.1)$ \\
L3 & $431(42.5)$ & $65(57.0)$ & $322(44.0)$ & $44(26.0)$ \\
Behaviour & & & & \\
B1 & $358(35.3)$ & $36(31.6)$ & $253(34.6)$ & $69(40.8)$ \\
B2 & $341(33.6)$ & $38(33.3)$ & $239(32.6)$ & $64(37.9)$ \\
B3 & $316(31.1)$ & $40(35.1)$ & $240(32.8)$ & $36(21.3)$ \\
\hline
\end{tabular}

For complex disease behaviour (stricturing [B2] and penetrating [B3]), $P<0.05$ compared with nonstricturing and nonpenetrating (B1) behaviour for all age groups. B3 excludes perianal fistulas and/or abscesses. L1 Ileum; L2 Colon; L3 Ileocolon

prior Vienna schema (2), this database was originally noted to be predominantly female $(56.1 \%)$, with $84.4 \%$ diagnosed before 40 years of age. In addition, disease was observed to be localized to the ileum in $25.3 \%$, colon in $27.2 \%$, ileocolon in $34.6 \%$ and upper gastrointestinal tract in $13.1 \%$ of patients, despite disease in other areas. Finally, disease behaviour was classified as stricturing (or stenosing) in $33.6 \%$ and penetrating (or perforating) in $37.2 \%$ of patients.

For all patients in the present study, office and inpatient hospitalization records, as well as endoscopic, radiological imaging, surgical and pathology reports, were recorded. Statistical analyses were perfomed using Student's $t$ test or $\chi^{2}$ analysis.

\section{Classification method}

In the present study, male and female patients were each classified based on a recently published schema (ie, the Montreal classification for Crohn's disease) (9).

Age at diagnosis: This Montreal schema presently defines two new age groups younger than 40 years of age at diagnosis, specifically a patient age group 16 years or younger (A1) and a second group for patients 17 to 40 years of age (A2). The previous category that included patients older than 40 years of age at diagnosis was not changed (A3).

Disease location and behaviour: Other defining features of the prior Vienna schema were used (8) but were modified by the Montreal schema (9).

First, disease location was defined as the maximal extent of disease or disease at the first resection (ie, L1 ileum, possibly involving cecum; L2 colon; L3 ileocolon, and L4 upper gastrointestinal tract). In the new Montreal schema, L4 is now listed as a modifier for L1, L2 and L3 (ie, so as to not disregard ileal and/or colon involvement if upper gastrointestinal tract disease is present) (9).

Second, disease behaviour definitions (eg, B1 nonstricturing and nonpenetrating, B2 stricturing and B3 penetrating) were modified. In the new Montreal schema, B1 disease behaviour was refined as an 'interim' category to define a more 'stable' behavioural phenotype (9). Based on previous studies (4) on the natural history of Crohn's disease from UBC hospital (Vancouver, British Columbia) and others $(10,11)$, a minimum of three to five years
TABLE 2

Upper gastrointestinal (UGI) tract involvement in Crohn's disease $(n=119)$

\begin{tabular}{lcccc}
\hline Site & $\begin{array}{c}\text { All, } \\
\mathbf{n}(\%)\end{array}$ & $\begin{array}{c}<17 \text { years, } \\
\mathbf{n}(\%)\end{array}$ & $\begin{array}{c}\mathbf{1 7 - 4 0} \text { years, } \\
\mathbf{n}(\%)\end{array}$ & $\begin{array}{c}>\mathbf{4 0} \text { years, } \\
\mathbf{n}(\%)\end{array}$ \\
\hline L1 & $30(25.2)$ & $4(16.7)$ & $23(27.1)$ & $3(30.0)$ \\
L2 & $14(11.8)$ & $3(12.5)$ & $9(10.6)$ & $2(20.0)$ \\
L3 & $72(60.5)$ & $17(70.8)$ & $50(58.8)$ & $5(50.0)$ \\
UGI only & $3(2.5)$ & $0(0.0)$ & $3(3.5)$ & $0(0.0)$ \\
\hline
\end{tabular}

For the ileocolon (L3) category, $P<0.05$ compared with the ileum (L1), colon (L2) or UGI categories

was required to define a 'stable' B1 disease behaviour phenotype. In the prior Vienna schema, disease behaviour was classified as penetrating if an intra-abdominal fistula, inflammatory mass and/or abscess developed, even if a coexisting stricture were present. In the new Montreal schema, a further disease behaviour modifier was proposed to exclude perianal fistulas and/or abscesses from classification as penetrating disease behaviour (11).

\section{RESULTS}

Patient population and classification

The 20-year-old accumulated database for the 1015 consecutively evaluated Crohn's disease patients is shown in Table 1. The predominant population was the 17- to 40-year age group $(\mathrm{P}<0.05)$ with disease mainly localized in the ileocolonic region $(\mathrm{P}<0.05)$. In the new Montreal classification (9), disease involvement in the upper gastrointestinal tract is considered to be a modifier, rather than a separate and exclusive disease site, as in the Vienna classification (8). Table 2 shows the locations of concomitant disease for 119 patients $(11.7 \%)$ with upper gastrointestinal tract involvement. Most patients with disease in the upper gastrointestinal tract also had disease in the ileocolonic region $(\mathrm{P}<0.05)$. There were only three patients with disease localized in the upper gastrointestinal tract alone, without evidence of ileal or colonic disease; all three patients were in the 17- to 40-year patient age group (ie, two male and one female). Overall, for disease behaviour, most patients $(657$ [64.7\%]; $\mathrm{P}<0.05)$ in the present cohort had disease that could be characterized as complex, being complicated with strictures (ie, stenosis) or penetrating (ie, perforating) complications. Similarly, complex disease (ie, with strictures or penetrating disease complications) was noted for each of the different age groups (younger than 17 years of age [68.4\%], 17 to 40 years of age [65.4\%], and older than 40 years of age [59.2\%]; all $\mathrm{P}<0.05)$.

\section{Sex distribution}

In the present series of 1015 consecutively evaluated patients with Crohn's disease, there were 449 male (44.2\%) and 566 female $(55.8 \%)$ patients, similar to earlier data that reflected a predominantly female population (2).

Figure 1 shows the locations or sites of disease for both male and female patients, expressed as percentages for the entire group. In the overall population group, no significant differences were detected between male and female patients for different disease sites. Most male $(\mathrm{n}=183$ [40.8\%]) and most female patients $(n=248[43.8 \%])$ had ileocolonic disease (both $\mathrm{P}<0.05)$. Concomitant involvement of an upper gastrointestinal 


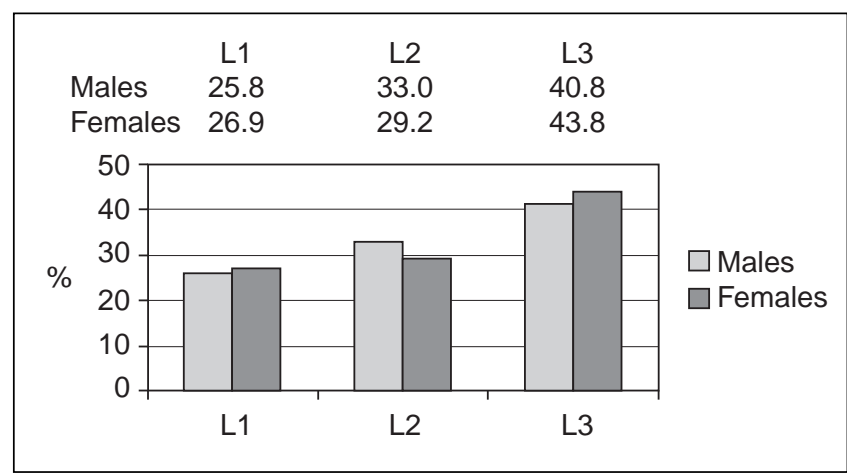

Figure 1) Percentages of males and females with disease localized at different sites ( $n=1012$; three patients had isolated upper gastrointestinal tract involvement). L1 Ileum; L2 Colon; L3 Ileocolon

tract site was similar in both males $(\mathrm{n}=58[13.4 \%])$ and females $(\mathrm{n}=59[10.4 \%])$.

Figure 2 shows the type of disease behaviour for both male and female patients, expressed as percentages for the entire group. In the overall population group, no significant differences were detected between males and females for different types of disease behaviour. Most males (281 [62.6\%]) and most females (376 [66.4\%]) had complex disease; their disease behaviour may be classified as either stricturing or penetrating.

In the present cohort, previously defined with the Vienna schema (7), 74 patients with B3 disease behaviour or penetrating disease (because of removal of the 'perianal disease only' modifier) were reclassified to either B1 'nonstricturing and nonpenetrating' disease behaviour (55 patients) or B2 stricturing disease behaviour (19 patients).

\section{Effect of age on disease location}

Table 1 also shows the effects of age at diagnosis on disease location for all patients with Crohn's disease. One of the most striking findings was the age-dependent effect for colonic disease. With increasing age at diagnosis, disease involvement within the colon alone was significantly increased $(\mathrm{P}<0.05)$, while ileocolonic disease involvement was decreased $(\mathrm{P}<0.05)$. Table 2 also shows that with increasing age at diagnosis, the percentages with concomitant disease in the upper gastrointestinal tract were progressively decreased (ie, younger than 17 years, $21.1 \%$; 17 to 40 years, $11.2 \%$; older than 40 years, $5.9 \%$; all $\mathrm{P}<0.05)$.

Similar results were seen with increasing age for both males and females. For both sexes over 40 years of age, more colonic disease involvement alone and less upper gastrointestinal tract disease were detected. These results suggest that there is a time-dependent effect of age at diagnosis on the extent of disease involvement in Crohn's disease. With increasing age at diagnosis, the extent of disease involvement is less, and more often, this remains localized to the colon alone.

\section{Effect of age on disease behaviour}

Table 1 shows the effects of age at diagnosis on disease behaviour for the entire Crohn's disease population. An age-related effect on the appearance of less complex 'inflammatory' or nonstricturing and nonpenetrating B1 disease behaviour was suggested if the diagnosis of Crohn's disease was established after 40 years of age compared with both younger adults or

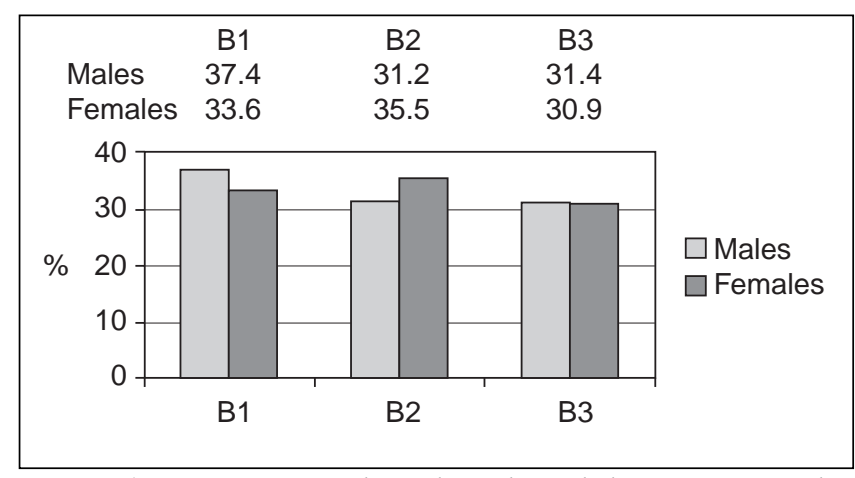

Figure 2) Percentages of males and females with different forms of disease behaviour. B1 Nonstricturing and nonpenetrating, or 'inflammatory'; B2 Stricturing or stenosing; B3 Penetrating or perforating

pediatric patients diagnosed before 17 years of age. The most striking finding, however, was that complex penetrating disease complications occur less often if Crohn's disease is initially diagnosed after 40 years of age $(\mathrm{P}<0.05)$.

Similar findings in both males and females were seen with increasing age.

These results suggest that there is a 'age at diagnosis'dependent effect on the appearance of complex penetrating disease complications. With increasing age at diagnosis, the complexity of disease appears to be less, particularly for penetrating disease, with the definition of more B1 'inflammatory' (ie, nonstricturing and nonpenetrating) disease behaviour.

\section{DISCUSSION}

Using a large, consecutively accumulated Crohn's disease patient database acquired over 20 years, the present study showed significant age-dependent effects in both males and females for the phenotypic clinical expression of this heterogeneous disorder. Although this is not a population-based study and the proportion of patients in each category may reflect referral bias, these results are consistent with findings in earlier historical studies (12-14), as well as investigations using the prior Vienna schema (2). In the present study, however, the newly developed Montreal schema (9) was used for classification of patients into more homogeneous or 'reagent-grade' groups.

Time-dependent effects, based on 'age at diagnosis', on both the site and extent of disease involvement appeared to be evident. For both males and females, more colonic disease and less upper gastrointestinal tract involvement were observed with increasing age. These results suggest that there is an effect of age at diagnosis on the extent of disease involvement in Crohn's disease. With increasing age at diagnosis, the extent of disease appears to be less and, more often, remains localized to the colon alone. These results, using the new Montreal classification method, are consistent with earlier studies (12-14) that also showed decreased small bowel and/or increased colonic involvement with older age.

The present study also suggested a time-dependent effect, based on 'age at diagnosis', on the clinical behaviour of Crohn's disease. More complex disease, particularly with penetrating disease complications, was more likely with a younger age at diagnosis, while less complex 'inflammatory' disease without significant complication, particularly penetrating disease, was 
more likely if diagnosis was established after 40 years of age. These results suggest that age at the time of diagnosis is a critical variable in determining the long-term outcome of Crohn's disease. Diagnosis at an earlier age appears to be associated with more extensive disease involvement of the gastrointestinal tract and more complex disease, particularly with penetrating disease complications.

The present study was not intended to directly compare the prior Vienna schema with the newly devised Montreal schema. The Vienna classification, however, was initially used to explore similarities and differences in Crohn's disease cohorts from Europe and North America, including Canada $(2,8)$. Later, it was used to explore the natural history of Crohn's disease, age-dependent changes in the phenotypic expression of the disease, and other factors, including the role of disease site and disease behaviour $(2-7,10,11)$. The Montreal schema was really a consensus document, and the present evaluation now provides the first independent verification that this classification can be applied to a Crohn's disease cohort. Classifications, such as the prior Vienna schema and the Montreal modification, however, will likely prove to be even more useful in the comparison of more homogeneous Crohn's disease populations from a global perspective, despite being derived from different geographical sites.

Although a need for segregation of the under 40-year-old population (at diagnosis) into different age groups was earlier appreciated by the investigator, leading to a prior modification of the Vienna classification $(5,7)$, the Montreal schema formalized this important distinction with a new under 17-year-old age group. In addition, the Vienna schema defined a distinctive but exclusive category for upper gastrointestinal tract disease, despite the presence of disease in other sites (eg,

\section{REFERENCES}

1. Fiocchi C. Inflammatory bowel disease: Etiology and pathogenesis. Gastroenterology 1998;115:182-205.

2. Freeman HJ. Application of the Vienna Classification for Crohn's disease to a single clinician database of 877 patients. Can J Gastroenterol 2001;15:89-93.

3. Freeman HJ. Familial Crohn's disease in single or multiple first-degree relatives. J Clin Gastroenterol 2002;35:9-13.

4. Freeman HJ. Natural history and clinical behavior of Crohn's disease extending beyond two decades. J Clin Gastroenterol 2003;37:216-9.

5. Freeman HJ. Comparison of longstanding pediatric-onset to adult-onset Crohn's disease. J Pediatr Gastroenterol Nutr 2004:39:183-6.

6. Freeman HJ. Long-term prognosis of early-onset Crohn's disease diagnosed in childhood or adolescence. Can J Gastroenterol 2004;18:655-9.

7. Freeman HJ. Age-dependent phenotypic clinical expression of Crohn's disease. J Clin Gastroenterol 2005;39:774-7.

8. Gasche C, Scholmerich J, Brynskov J, et al. A simple classification of Crohn's disease: Report of a Working Party for the World Congresses of Gastroenterology, Vienna 1998. Inflamm Bowel Dis 2000;6:8-15.

9. Silverberg MS, Satsangi J, Ahmad T, et al. Toward an integrated clinical, molecular and serological classification of inflammatory ileum, colon or both). Although isolated Crohn's disease in the upper gastrointestinal tract alone may occur, it is rare (2). The new Montreal schema now removes the exclusive nature of this aspect of the classification schema. Moreover, the earlier observation that some patients with perineal fistula disease or abscesses may exhibit a different disease behaviour than those with penetrating disease complications in other sites was explored here (11). Overall, reclassification using the Montreal schema did result in reduced numbers of those with B3 penetrating disease behaviour. However, many of these reclassified patients were male. In contrast, female patients with perineal disease often have penetrating genital complications (eg, vaginal fistula), and their classification was not altered. Finally, some patients in the present study, especially those classified with 'inflammatory' disease, may require a more prolonged period of follow-up beyond the three to five years before a 'final' classification category can be established. Indeed, earlier studies from this centre (4) have already shown that disease behaviour may change with time, even up to 10 years or more after the initial diagnosis, likely reflecting the true natural history of this chronic inflammatory disease process. The mean follow-up period exceeded 10 years and, for many patients, even 20 years. As has been previously shown, even this amount of time represents a very limited period in the natural history of a genetically and phenotypically complex disease such as Crohn's disease $(6,15)$, including disease that may be first documented in the very elderly (16). Use of a standardized schema for classification, however, may be helpful for clinicians caring for these difficult patients to more precisely explore the longitudinal effects of smoking and other dietary factors, along with the role of different nutritional and treatment regimens on the natural history of Crohn's disease.

bowel disease: Report of a Working Party of the 2005 Montreal World Congress of Gastroenterology. Can J Gastroenterol 2005;19(Suppl A):5-36.

10. Cosnes J, Cattan S, Blain A, et al. Long-term evolution of disease behavior of Crohn's disease. Inflamm Bowel Dis 2002;8:244-50

11. Louis E, Collard A, Oger AF, Degroote E, Aboul Nasr El Yafi FA Belaiche J. Behavior of Crohn's disease according to the Vienna classification: Changing pattern over the course of the disease. Gut 2001;49:777-82.

12. Harper PC, McAuliffe TL, Beeken WL. Crohn's disease in the elderly. A statistical comparison with younger patients matched for sex and duration of disease. Arch Intern Med 1986;146:753-5.

13. Farmer RG, Michener WM. Prognosis of Crohn's disease with onset in childhood or adolescence. Dig Dis Sci 1979;24:752-7.

14. Polito JM II, Childs B, Mellits ED, Tokayer AZ, Harris ML, Bayless TM. Crohn's disease: Influence of age at diagnosis on site and clinical type of disease. Gastroenterology 1996;111:580-6.

15. Freeman HJ. Temporal and geographic evolution of longstanding Crohn's disease over more than 50 years. Can J Gastroenterol 2003;17:696-700.

16. Freeman HJ. Crohn's disease defined in three elderly sisters. Can J Gastroenterol 2005;19:251-2. 


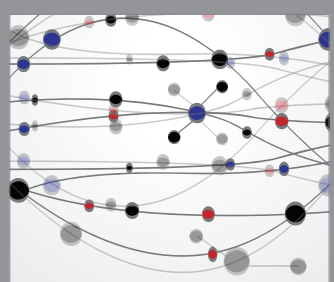

The Scientific World Journal
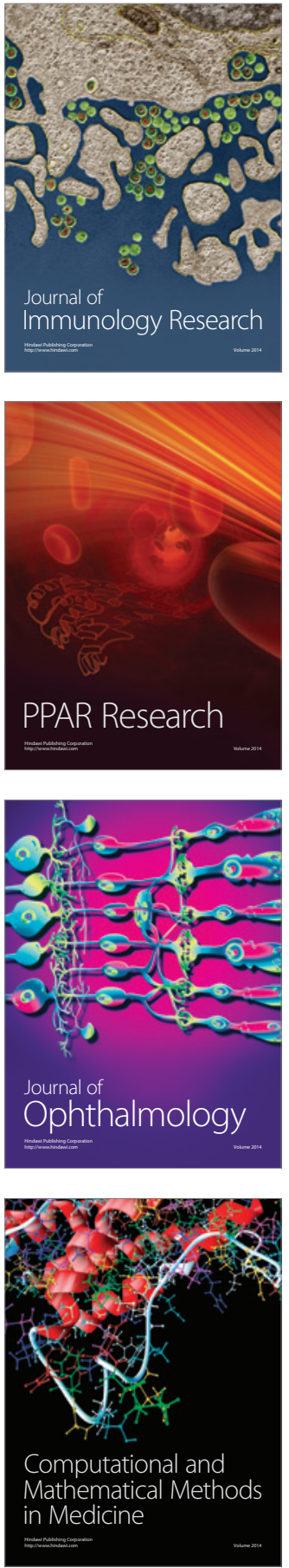

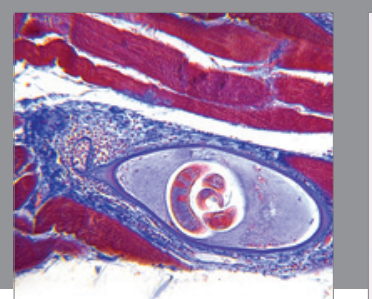

Gastroenterology Research and Practice

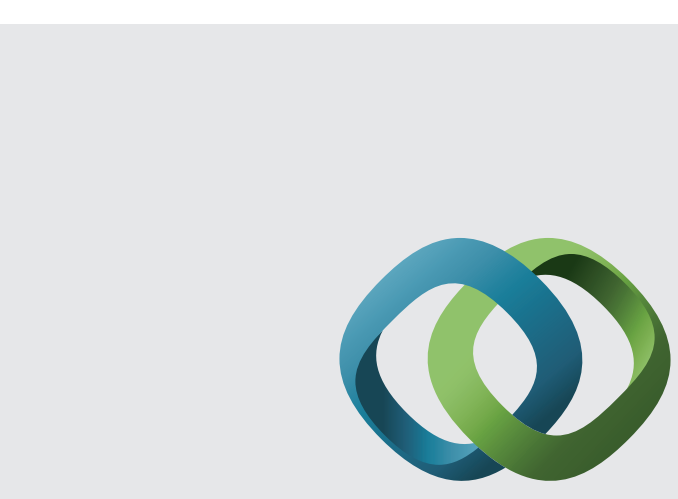

\section{Hindawi}

Submit your manuscripts at

http://www.hindawi.com
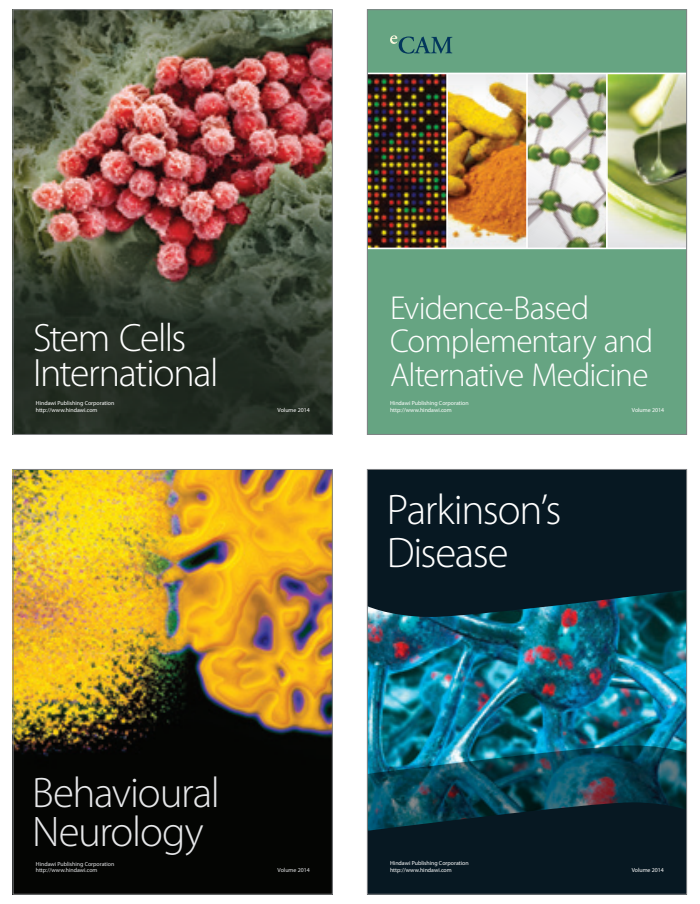
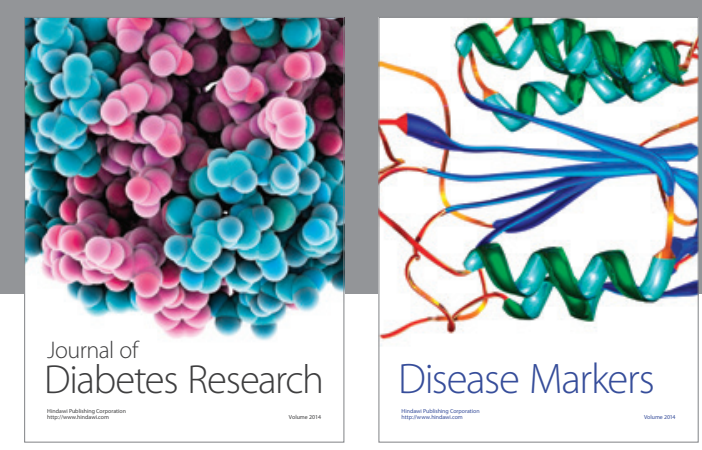

Disease Markers
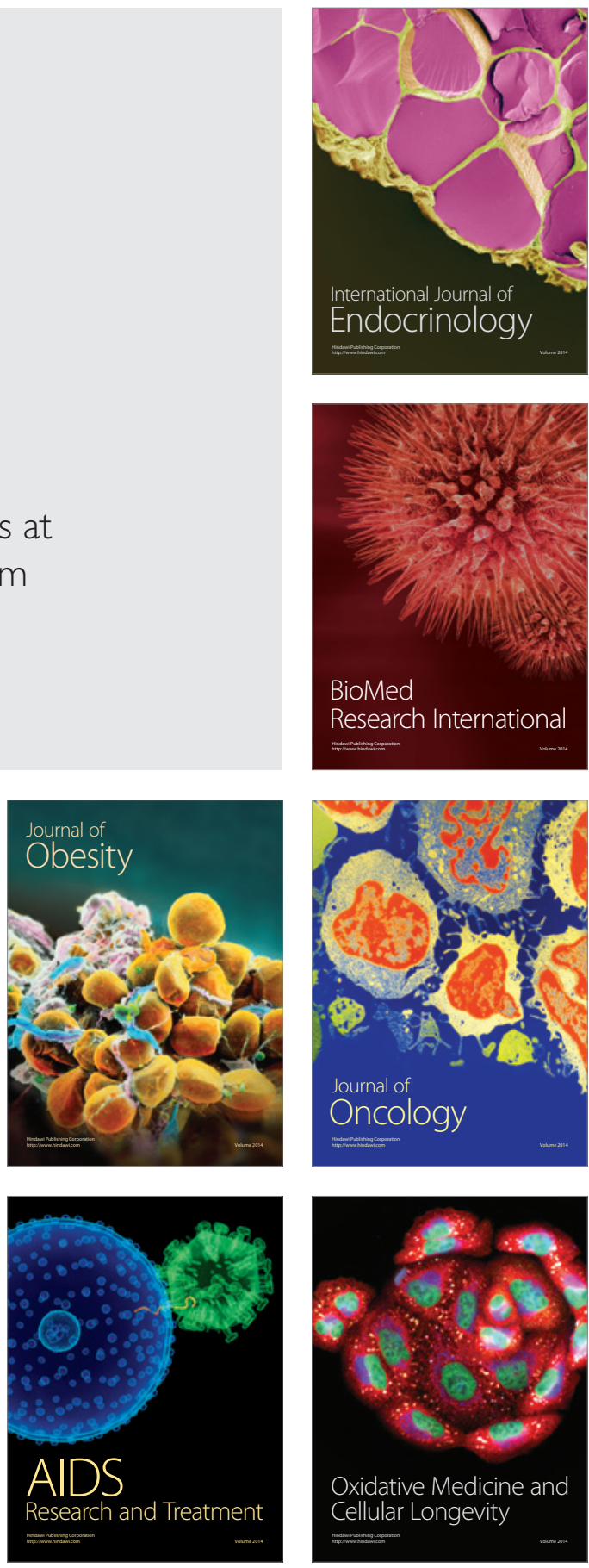